\title{
Intrathyroidal Parathyroid Carcinoma in Chronic Kidney Disease: A Case Report and Review of Literature
}

\author{
Moo Keon Kim, Chang Myeon Song, Kyung Tae, and Yong Bae Ji \\ Department of Otolaryngology-Head and Neck Surgery, College of Medicine, Hanyang University, Seoul, Korea
}

\section{만성 신장 질환을 동반한 갑상선 내 부갑상선암 1 예}

김무건 · 송창면 · 태 경 · 지용배

한양대학교 의과대학 이비인후-두경부외과학교실

\author{
Received June 12, 2019 \\ Revised August 14, 2019 \\ Accepted August 21, 2019 \\ Address for correspondence \\ Yong Bae Ji, MD, PhD \\ Department of Otolaryngology- \\ Head and Neck Surgery, \\ College of Medicine, \\ Hanyang University, \\ 222 Wangsimni-ro, Seongdong-gu, \\ Seoul 04763, Korea \\ Tel $+82-31-560-2297$ \\ Fax $+82-31-566-4884$ \\ E-mail jyb20000@hanyang.ac.kr
}

When parathyroid carcinoma occurs in the thyroid gland, it is very difficult to diagnose before surgery because imaging studies and aspiration cytology cannot distinguish parathyroid carcinoma from thyroid nodule or benign parathyroid disease. A 53-year-old male was referred to our hospital for assessment of hypercalcemia. He had suffered from chronic kidney disease for 13 years. A $2.5 \times 1.5 \mathrm{~cm}$ hypoechoic nodule was noted in the left thyroid gland on ultrasonography, and it showed increased uptake on the sestamibi scan. Fine needle aspiration biopsy revealed it to be a parathyroid lesion, which was confirmed by surgery as parathyroid carcinoma completely surrounded by normal thyroid parenchyme. Because ultrasonography and aspiration cytology have only a limited role in distinguishing parathyroid carcinoma from thyroid neoplasm, suspicion of parathyroid carcinoma before or during surgery through careful examination can lead to complete resection at the initial surgery.

Korean J Otorhinolaryngol-Head Neck Surg 2019;62(12):740-6

Key Words Chronic kidney disease · Hyperparathyroidism · Parathyroid carcinoma · Thyroid nodule.

\section{Introduction}

The diagnosis of parathyroid carcinoma before or during surgery is challenging, especially when the tumor occurs in an unusual location. When this cancer occurs within the thyroid gland, preoperative imaging studies including ultrasound, CT scan, and sestamibi scan have a limited role in distinguishing it from thyroid nodule and benign parathyroid lesion. Even fine needle aspiration biopsy (FNAB) may be confusing because of its cellular similarity to follicular thyroid lesions. ${ }^{1,2)}$

Chronic kidney disease may cause hyperparathyroidism. Physiologic regulation of parathyroid hormone secretion can

This is an Open Access article distributed under the terms of the Creative Commons Attribution Non-Commercial License (https://creativecommons.org/licenses/by-nc/4.0) which permits unrestricted non-commercial use, distribution, and reproduction in any medium, provided the original work is properly cited. cause secondary hyperparathyroidism in response to vitamin D deficiency or hypocalcemia, which are common in patients with chronic kidney disease. Long-term secondary hyperparathyroidism with hypertrophy of the parathyroid gland and decreased function of parathyroid hormone regulation in response to serum calcium level are classified as having tertiary hyperparathyroidism. Therefore, parathyroid lesions in patients with chronic kidney disease are not uncommon and can complicate the diagnosis of parathyroid carcinoma.

We introduce a case of intrathyroidal parathyroid carcinoma mimicking a thyroid nodule in a 53-year-old male patient with chronic kidney disease, along with a review of the literature. 


\section{Case}

A 53-year-old man was referred to our institution with hypercalcemia with hyperparathyroidism. He suffered from chronic fatigue and multiple joint pain. He had diabetes, hypertension, and chronic kidney disease from 13 years ago and was on hemodialysis. A $1.5 \times 1.5 \mathrm{~cm}$ firm mass was palpated at the left lobe of the thyroid gland on physical examination, but he reported no problems with his voice or swallowing. Laboratory tests showed an elevated blood urea nitrogen of $65 \mathrm{mg} /$ $\mathrm{dL}$ (reference range, 7-20), a creatinine of $10.2 \mathrm{mg} / \mathrm{dL}$ (reference range, $0.5-1.4$ ), a serum calcium of $9.7 \mathrm{mg} / \mathrm{dL}$ (reference range, 8.2-10.7) and a low phosphate level of $7.0 \mathrm{mg} / \mathrm{dL}$ (reference range, 8.4-10.2). Intact parathyroid hormone (PTH) level was markedly elevated at $3115 \mathrm{pg} / \mathrm{mL}$ (reference range, 15-55), but thyroid function tests were within normal ranges. Normal 24-hour urinary catecholamines, calcitonin, and pituitary function excluded multiple endocrine neoplasia.

On thyroid neck ultrasonography, a $2.0 \times 1.5 \mathrm{~cm}$ lobulated hypoechoic lesion with rim calcification was found in the middle portion of the left thyroid gland (Fig. 1). FNAB was done at this lesion and showed findings consistent with a "parathyroid lesion." Even though the tumor was located within the thyroid gland, FNAB result and markedly increased PTH level suggested parathyroid tumor. Furthermore, tertiary parathyroid hyperplasia could not be excluded because the patient had chronic kidney disease for a long time and was on hemodialysis. So, we did ${ }^{99 \mathrm{~m}} \mathrm{TC}$-sestamibi parathyroid scan and it showed increased uptake at the left side of the thyroid gland on 10-minute and 2-hour delayed images (Fig. 2).

So, thyroid lobectomy or parathyroidectomy was planned. Because parathyroid gland hyperplasia could not be exclud-

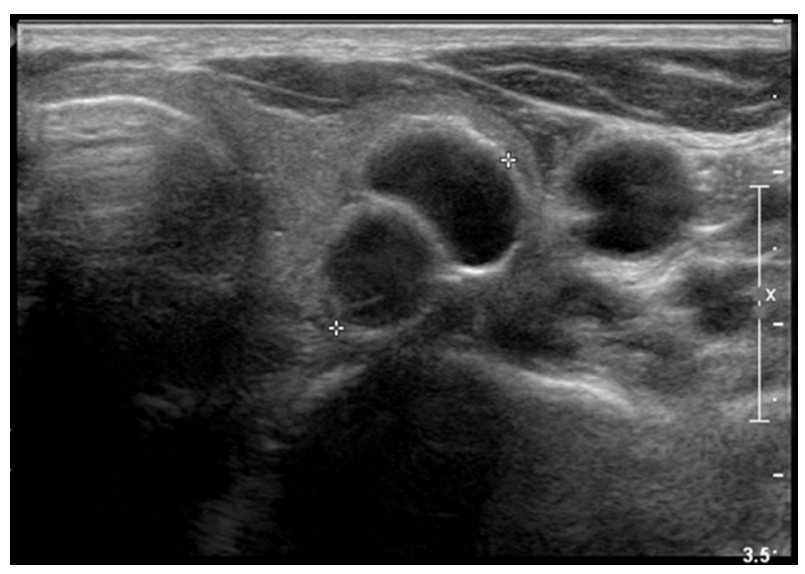

Fig. 1. Ultrasonographic findings. A $2 \times 1.5 \mathrm{~cm}$ lobulated hypoechoic lesion with rim calcification was found in the middle portion of the left thyroid gland. ed, we used midline approach by dividing strap muscles for four gland exploration. A $2.5 \times 1.5 \mathrm{~cm}$ mass was found in the left lobe of the thyroid gland intraoperatively, which was located within the thyroid gland and surrounding thyroid gland tissue was grossly intact. The left inferior parathyroid gland could not be identified, but the other 3 parathyroid glands were grossly intact. Therefore, a small piece of the left superior parathyroid gland was obtained and was found to be normal parathyroid gland on frozen biopsy. So, left thyroid lobectomy was performed because the tumor was located within the thyroid gland and parathyroid carcinoma was suspected due to markedly high parathyroid hormone level. Several slightly enlarged lymph nodes in the left paratracheal region were harvested (Fig. 3). The thyroid specimen was sent to the pathology department for frozen biopsy and was revealed to be a "parathyroid lesion" confined to the thyroid gland. Permanent biopsy revealed that the $1.8 \times 1.3 \mathrm{~cm}$ mass

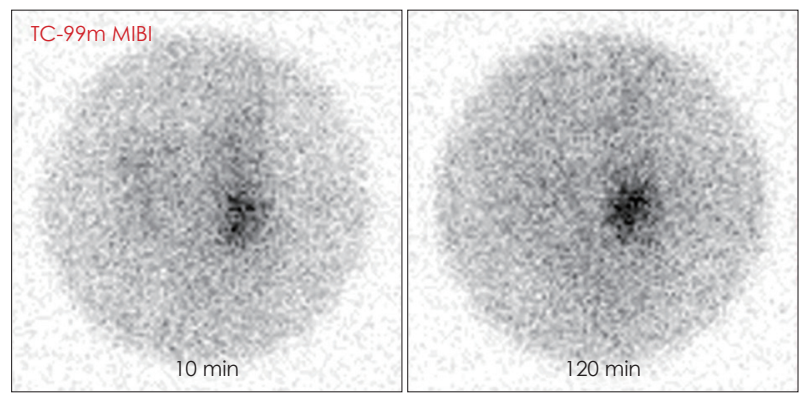

Fig. 2. Sestamibi scan findings. Increased uptake was found at the left side of the thyroid gland on 10- and 120-minute delayed images.

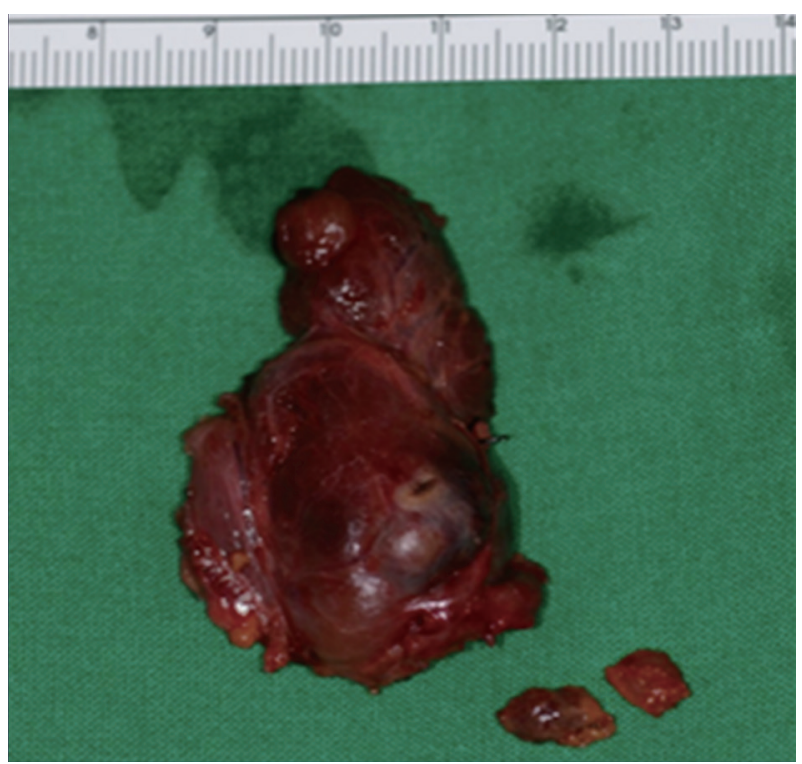

Fig. 3. Operative findings. A $2.5 \times 1.5 \times 1.0 \mathrm{~cm}$ mass was found in the left lobe of the thyroid gland, and several enlarged lymph nodes were found at the left paratracheal region. 
was parathyroid carcinoma completely surrounded by normal thyroid gland tissue. It consisted of chief cells with moderate dysplasia and had invaded into the thyroid gland parenchyma through the tumor capsule (Fig. 4). However, there was no lymph node metastasis. PTH dropped to $75 \mathrm{pg} / \mathrm{mL}$ on the first postoperative day. Postoperative care including oral vitamin D and calcium supplements with calcium gluconate injections were provided to prevent hypocalcemic symptoms from hungry bone syndrome. Six days after surgery, the patient was discharged without sequelae. PTH increased to 107 $\mathrm{pg} / \mathrm{mL}$ during the following year, as determined at an outpatient clinic, but it was $149 \mathrm{pg} / \mathrm{mL}$ at the last visit in 3 years after surgery. Moreover, there was no evidence of recurrence on imaging studies including ultrasonography, CT scan, 18Ffluorodeoxyglucose positron emission tomography (PET) scan, and sestamibi scan. Therefore, the patient was followed with medical treatment only, because the increased PTH was attributable to chronic kidney disease rather than recurrence of parathyroid carcinoma.
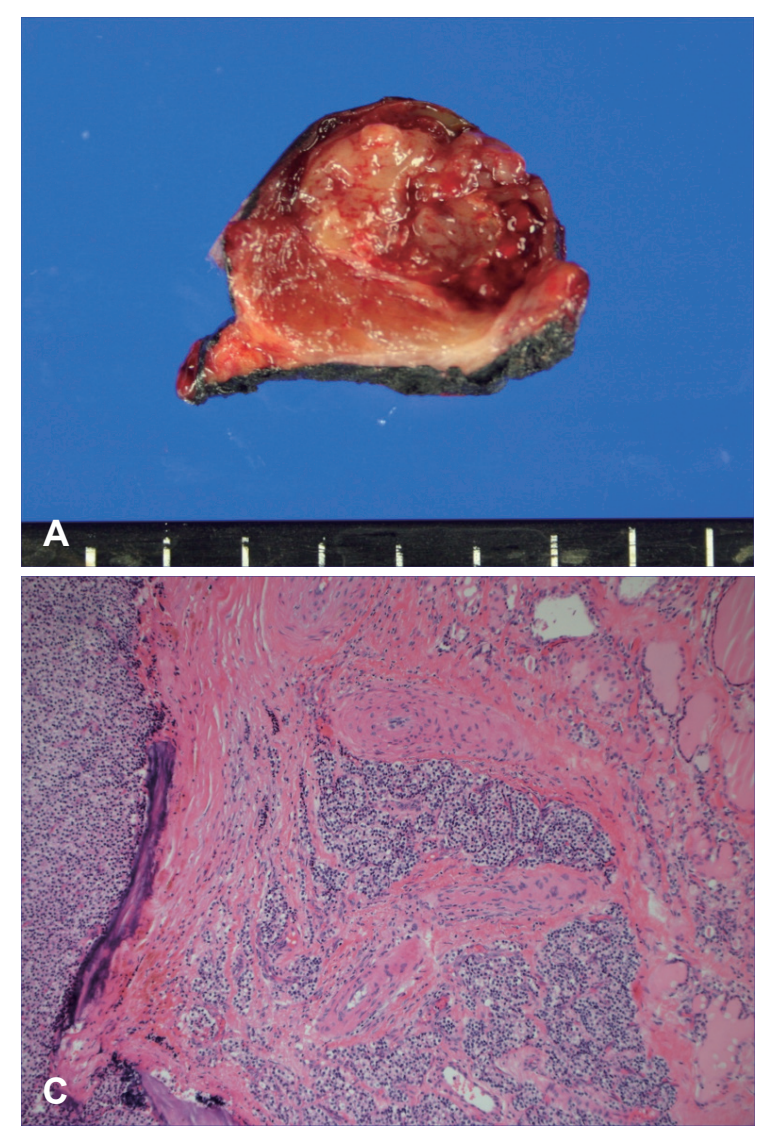

\section{Discussion}

Parathyroid carcinoma is a very rare cancer that accounts for $0.005 \%$ of all cancers. The incidence in patients presenting with primary hyperparathyroidism ranges from less than $0.5 \%$ to $3 \%{ }^{4,5)}$

Clinical and laboratory findings may suggest parathyroid carcinoma, however, these findings are nonspecific. Biochemically, the degree of hypercalcemia is more marked in patients with carcinoma $(3.75-4.0 \mathrm{mmol} / \mathrm{L})$ than in benign primary hyperparathyroidism $(2.7-2.9 \mathrm{mmol} / \mathrm{L}){ }^{6}{ }^{6}$ In case of parathyroid carcinoma, the PTH levels are also significantly higher, reported to be greater than 5 to 10 times the normal range. In contrast to benign primary hyperparathyroidism, parathyroid carcinoma patients usually present with palpable mass and end-organ diseases such as osteitis fibrosa cystica, nephrolithiasis and renal and bone disease. ${ }^{7,8)}$ FNAB for parathyroid lesions is helpful in identifying or at least suspecting parathyroid origin in unusually located nodules, because imaging studies including ultrasound, CT, and sestamibi scan have
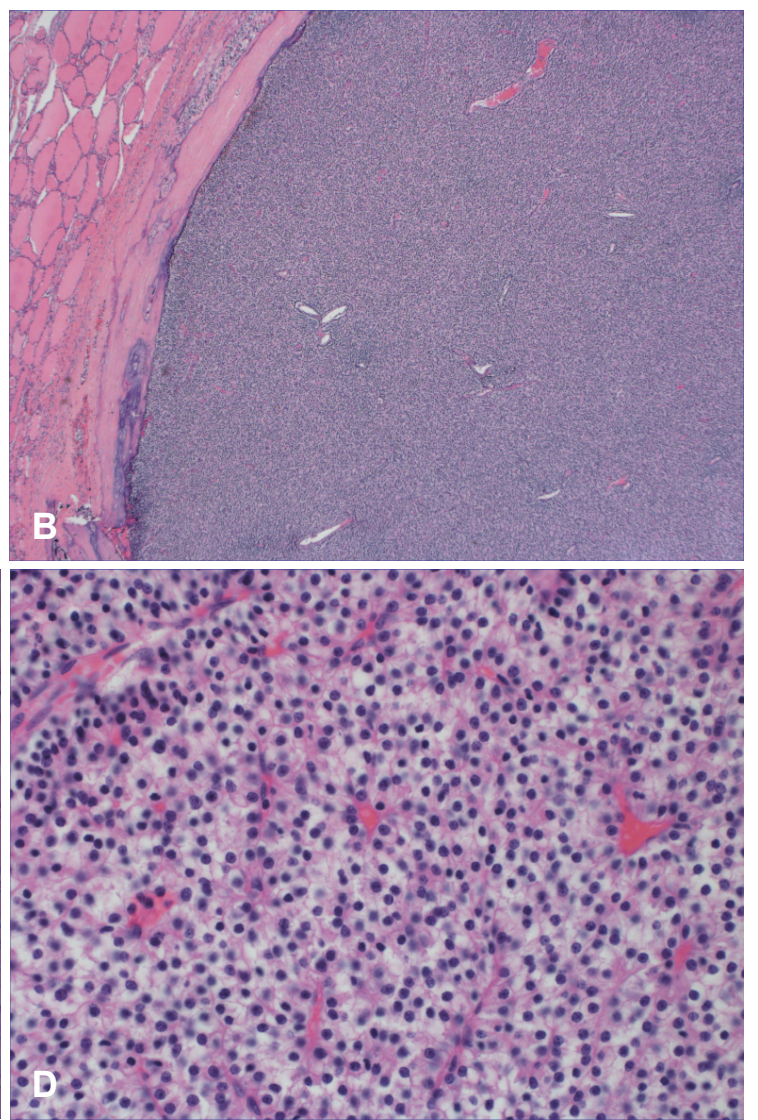

Fig. 4. Pathologic findings. The gross cut surface shows a yellowish irregular mass confined tothe thyroid gland (A). An encapsulated mass was found in low magnification view (B: H\&E stain, $\times 40)$, Tumor cells invading into the thyroid gland parenchyma through the capsule (C: H\&E stain, $\times 100)$, The mass consists of chief cells with moderate dysplasia andis compatible with parathyroid carcinoma (D: H\&E stain, $\times 400)$. H\&E: hematoxylin and eosin. 
little role in the diagnosis of parathyroid carcinoma, although they are helpful in localization.

However, differentiating parathyroid carcinoma from adenoma may be impossible on cytology, and parathyroid carcinoma can be confused with several thyroid lesions because they have overlapping cytologic features and some cytomorphologic similarities such as tissue fragments with papillary architecture, epithelial cells arranged in a microfollicular pattern, and colloid-like material in the background. ${ }^{1,2)}$ Moreover, the presence of oncocytic cells and naked nuclei of chief cells in the parathyroid are hard to distinguish from Hurthle cells and lymphocytes, respectively. Therefore, the differential diagnosis should include not only parathyroid adenoma and parathyroid hyperplasia, but also papillary thyroid carcinoma, anaplastic thyroid cancer, and even metastatic renal cell carcinoma. ${ }^{9)}$

Moreover, histologic findings alone are not sufficient for diagnosis of parathyroid carcinoma without malignant histologic features of capsular or neurovascular invasions and/or metastases. The generally accepted histopathologic features of parathyroid carcinoma include trabecular architecture, mitotic figures, thick fibrous bands, and capsular and blood vessel invasion. Immunohistochemical staining for Ki-67, PRAD1/ Cyclin D1, p27, and parafibromin is reported to be helpful for diagnosis of parathyroid carcinoma. ${ }^{10,11)}$

Unusual location of the parathyroid also complicates the diagnosis of parathyroid carcinoma. Parathyroid carcinoma can occur anywhere that ectopic parathyroid glands can be located. Several previous studies have reported that parathyroid glands are found in an ectopic location $6 \%$ to $22 \%$ of the time, and these can be one of the four parathyroid glands or a supernumerary gland. Their locations vary and can include the retro/paraesophageal space, the mediastinum, intrathymic, intrathyroidal sites, the carotid sheath, and in a high undescended cervical position. $^{12,13)}$

The intrathyroidal parathyroid gland is defined as a gland surrounded by thyroid tissue and should be differentiated from subcapsular parathyroid glands. The incidence of intrathyroidal parathyroid gland ranges from $0.5 \%$ to $4 \%$ and might be higher in patients with hyperparathyroidism. ${ }^{14-16)}$ The origin of intrathyroidal parathyroid gland is not fully understood, but it can be either superior or inferior or even supernumerary.

Embryologically, the superior parathyroid gland can be included within the thyroid during the fusion of the ultimobranchial bodies with the median thyroid rudiment. ${ }^{15)}$ However, some authors found the intrathyroid parathyroid gland locat- ed in the lower third of the thyroid lobe, which should be considered as an inferior parathyroid gland. ${ }^{16)}$

To the best of our knowledge, only 14 cases of intrathyroidal parathyroid carcinoma have been reported (Table 1). ${ }^{17-30)}$ All of these cases presented with hypercalcemia with or without a neck mass. The PTH level was higher than $200 \mathrm{pg} / \mathrm{mL}$ in all cases, and some of them were higher than $1000 \mathrm{pg} / \mathrm{mL}$. Sestamibi scan showed increased uptake in the respective lobe for most cases. FNAB was performed in seven cases, and most of them were misinterpreted as a follicular thyroid lesion or poorly differentiated thyroid carcinoma. Parathyroid lesion was reported in only 2 of these cases, and none of the cases had suspected parathyroid carcinoma on FNAB. Frozen biopsy results were described in 6 cases, and parathyroid carcinoma was suspected in only 2 cases. Oncologic outcomes were mentioned in 12 cases, none of which experienced recurrence, although the follow-up period was too short in most cases (1 month-5 years).

As there is no reliable preoperative diagnostic tool for parathyroid carcinoma, suspicion of parathyroid carcinoma preoperatively or intraoperatively is important for establishing proper surgical strategy. Although laboratory findings alone cannot distinguish parathyroid carcinoma from other hyperfunctioning lesions, PTH level in carcinoma is usually higher than in benign parathyroid lesion. The present case showed a high PTH level of $3115 \mathrm{pg} / \mathrm{mL}$. We could not confirm parathyroid carcinoma even on frozen biopsy in this case, but we removed the entire left thyroid and suspicious lymph nodes.

Patients with parathyroid carcinoma should undergo a comprehensive excision at the time of initial surgery. Complete resection frequently requires excision of the ipsilateral thyroid lobe, overlying strap musculature, and adjacent soft tissues. Because pathologic confirmation of parathyroid carcinoma is not always possible during surgery clinical findings such as preoperative imaging, PTH level or intraoperative finding is important. Because occult lymphatic metastasis is not common, prophylactic neck dissection is not recommended. ${ }^{4,5,31,32)}$

Parathyroid carcinoma is known as a slow-growing and often indolent but progressive tumor. It invades surrounding tissues and metastasizes both hematogeneously and, less commonly, via lymphatics. Complete tumor resection is important for improving prognosis. A higher 5-year survival rate was reported when ipsilateral hemithyroidectomy accompanied the initial resection $(90.0 \%$ with hemithyroidectomy and $82.5 \%$ without hemithyroidectomy). ${ }^{33)}$ A national cancer data base study reported 5-and 10-year overall survival rates of $82.3 \%$ 


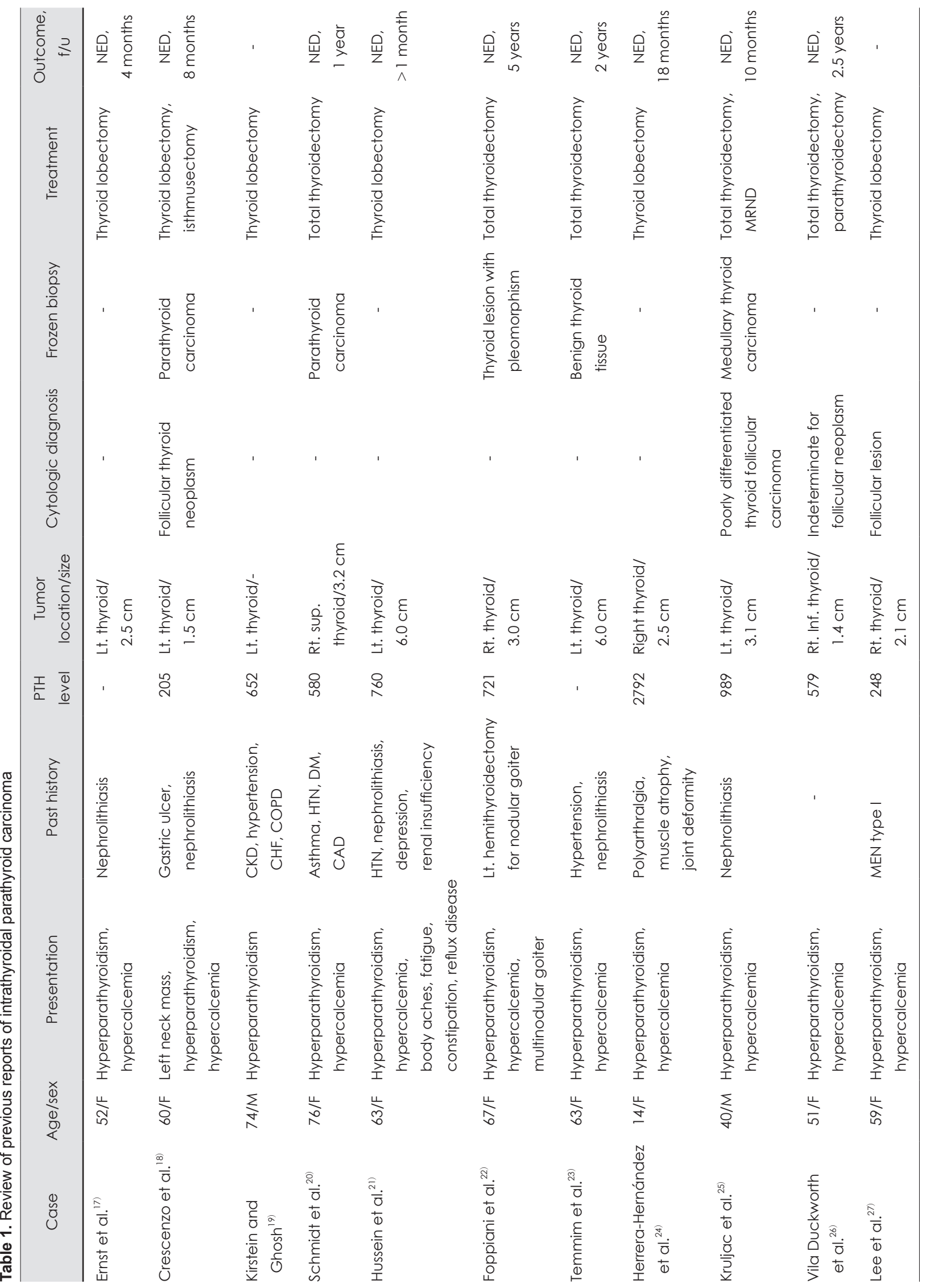




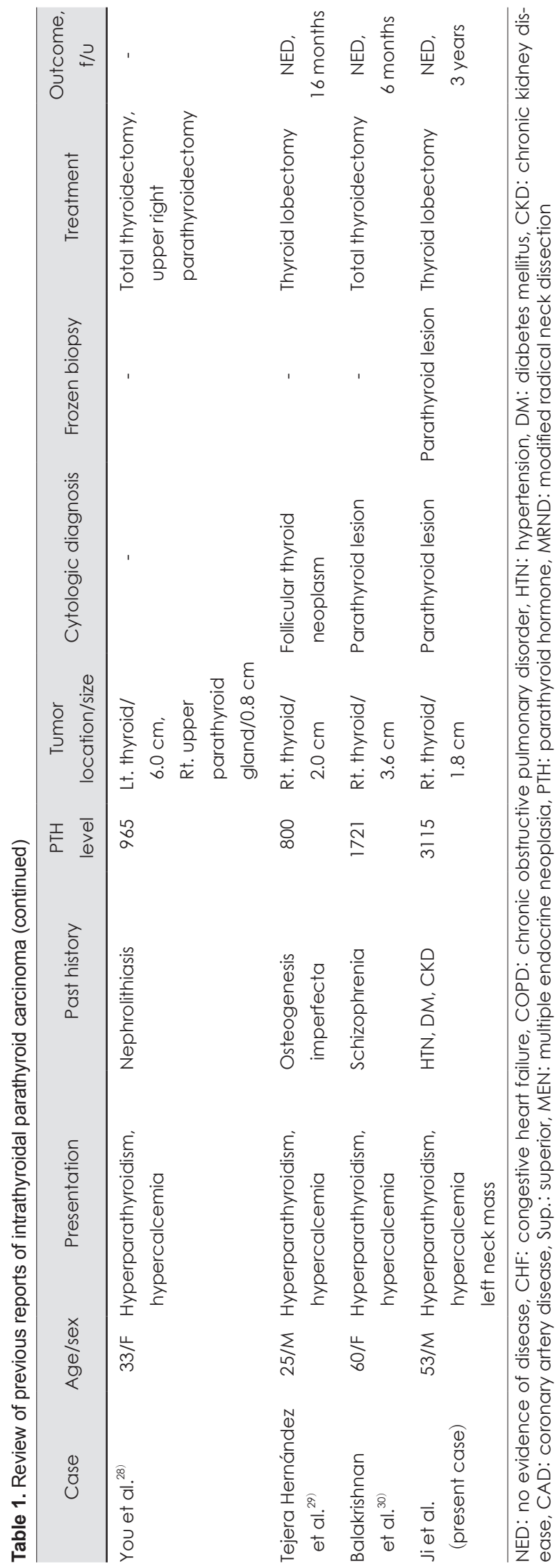

and $66 \%$, respectively. ${ }^{34)}$

In this case, the left inferior parathyroid gland could not be identified during the operation, and a thyroid nodule was reported as a parathyroid lesion on the frozen biopsy. Thyroid lobectomy and left paratracheal lymph node biopsy were performed. Because the tumor was confined to the thyroid gland and parathyroid hormone levels remained stable but high, we followed the patient without adjuvant therapy. During the 3 years of follow-up, PTH increased to around $120 \mathrm{pg} / \mathrm{mL}$ due to chronic kidney disease, but there was no evidence of recurrence on imaging studies including ultrasonography, CT scan, PET/CT scan, and sestamibi scan.

In conclusion, parathyroid lesion including carcinoma should be suspected when PTH is substantially increased, although parathyroid carcinoma is uncommon. Clinicians should be aware that masses in unusual locations, even in the thyroid gland, might be parathyroid carcinoma, because parathyroid glands can exist at various ectopic locations. Because there are no reliable preoperative diagnostic tools for parathyroid carcinoma, suspicion of parathyroid carcinoma before or during surgery is important. Suspicion and careful examination can lead to complete resection at the initial surgery, which is important for the best chance of cure.

\section{Acknowledgments}

None.

\section{ORCID}

Yong Bae Ji https://orcid.org/0000-0002-0182-7865

\section{REFERENCES}

1) Shi C, Guan H, Qi W, Ji J, Wu J, Yan F, et al. Intrathyroidal parathyroid adenoma: Diagnostic pitfalls on fine-needle aspiration: Two case reports and literature review. Diagn Cytopathol 2016;44(11):921-925.

2) Paker I, Yilmazer D, Yandakci K, Arikok AT, Alper M. Intrathyroidal oncocytic parathyroid adenoma: A diagnostic pitfall on fine-needle aspiration. Diagn Cytopathol 2010;38(11):833-6.

3) Kim BS, Ryu HS, Kang KH, Park SJ. Parathyroid carcinoma in tertiary hyperparathyroidism. Asian J Surg 2016;39(4):255-9.

4) Hundahl SA, Fleming ID, Fremgen AM, Menck HR. Two hundred eighty-six cases of parathyroid carcinoma treated in the U.S. between 1985-1995: A National Cancer Data Base Report. The American College of Surgeons Commission on Cancer and the American Cancer Society. Cancer 1999;86(3):538-44.

5) Shane E. Clinical review 122: Parathyroid carcinoma. J Clin Endocrinol Metab 2001;86(2):485-93.

6) Iacobone M, Lumachi F, Favia G. Up-to-date on parathyroid carcinoma: Analysis of an experience of 19 cases. J Surg Oncol 2004;88(4): 223-8.

7) Obara T, Fujimoto Y. Diagnosis and treatment of patients with parathyroid carcinoma: An update and review. World J Surg 1991; 15(6):738-44.

8) Koea JB, Shaw JH. Parathyroid cancer: Biology and management. 
Surg Oncol 1999;8(3):155-65.

9) Bondeson L, Bondeson AG, Nissborg A, Thompson NW. Cytopathological variables in parathyroid lesions: A study based on 1,600 cases of hyperparathyroidism. Diagn Cytopathol 1997; 16(6):476-82.

10) Stojadinovic A, Hoos A, Nissan A, Dudas ME, Cordon-Cardo C, Shaha AR, et al. Parathyroid neoplasms: Clinical, histopathological, and tissue microarray-based molecular analysis. Hum Pathol 2003; 34(1):54-64.

11) Tan MH, Morrison C, Wang P, Yang X, Haven CJ, Zhang C, et al. Loss of parafibromin immunoreactivity is a distinguishing feature of parathyroid carcinoma. Clin Cancer Res 2004;10(19):6629-37.

12) Roy M, Mazeh H, Chen H, Sippel RS. Incidence and localization of ectopic parathyroid adenomas in previously unexplored patients. World J Surg 2013;37(1):102-6.

13) Phitayakorn R, McHenry CR. Incidence and location of ectopic abnormal parathyroid glands. Am J Surg 2006;191(3):418-23.

14) Thompson NW, Eckhauser FE, Harness JK. The anatomy of primary hyperparathyroidism. Surgery 1982;92(5):814-21.

15) Wang C. The anatomic basis of parathyroid surgery. Ann Surg 1976;183(3):271-5.

16) Wheeler MH, Williams ED, Wade JS. The hyperfunctioning intrathyroidal parathyroid gland: A potential pitfall in parathyroid surgery. World J Surg 1987;11(1):110-4.

17) Ernst M, Lippmann M, Fleige B. [Primary hyperparathyroidism in intrathyroid parathyroid cancer]. Zentralbl Chir 1993;118(11):682-5.

18) Crescenzo DG, Shabahang M, Garvin D, Evans SR. Intrathyroidal parathyroid cancer presenting as a left neck mass. Thyroid 1998; 8(7):597-9.

19) Kirstein LJ, Ghosh BC. Intrathyroid parathyroid carcinoma. J Surg Oncol 2001;77(2):136-8.

20) Schmidt JL, Perry RC, Philippsen LP, Wu HH. Intrathyroidal parathyroid carcinoma presenting with only hypercalcemia. Otolaryngol Head Neck Surg 2002;127(4):352-3.

21) Hussein WI, El-Maghraby TA, Al-Sanea O. Hyperfunctioning intrathyroidal parathyroid carcinoma. Saudi Med J 2006;27(8): 1226-9.

22) Foppiani L, Del Monte P, Sartini G, Arlandini A, Quilici P, Bandelloni $\mathrm{R}$, et al. Intrathyroidal parathyroid carcinoma as cause of hypercalcemia and pitfall of localization techniques: Clinical and biologic features.
Endocr Pract 2007;13(2):176-81.

23) Temmim L, Sinowatz F, Hussein WI, Al-Sanea O, El-Khodary H. Intrathyroidal parathyroid carcinoma: A case report with clinical and histological findings. Diagn Pathol 2008;3:46.

24) Herrera-Hernández AA, Aranda-Valderrama P, Díaz-Pérez JA, Herrera LP. Intrathyroidal parathyroid carcinoma in a pediatric patient. Pediatr Surg Int 2011;27(12):1361-5.

25) Kruljac I, Pavic I, Matesa N, Mirosevic G, Maric A, Becejac B, et al. Intrathyroid parathyroid carcinoma with intrathyroidal metastasis to the contralateral lobe: Source of diagnostic and treatment pitfalls. Jpn J Clin Oncol 2011;41(9):1142-6.

26) Vila Duckworth L, Winter WE, Vaysberg M, Moran CA, Al-Quran SZ. Intrathyroidal parathyroid carcinoma: Report of an unusual case and review of the literature. Case Rep Pathol 2013;2013:198643.

27) Lee KM, Kim EJ, Choi WS, Park WS, Kim SW. Intrathyroidal parathyroid carcinoma mimicking a thyroid nodule in a MEN type 1 patient. J Clin Ultrasound 2014;42(4):212-4.

28) You WY, Han YM, Choi YH. Intrathyroidal parathyroid carcinoma: A case report. J Korean Soc Radiol 2015;72(5):319-23.

29) Tejera Hernández AA, Gutiérrez Giner MI, Vega Benítez V, Fernández San Millan D, Hernández Hernández JR. Intrathyroidal parathyroid carcinoma. A case report and review of literature. Endocrinol Nutr 2016;63(1):46-8.

30) Balakrishnan M, George SA, Rajab SH, Francis IM, Kapila K. Cytological challenges in the diagnosis of intrathyroidal parathyroid carcinoma: A case report and review of literature. Diagn Cytopathol 2018;46(1):47-52.

31) Tae K, Lee YS, Kim KR, Lee HS, Park DW, Park YS, et al. Radiologic diagnosis and surgical treatment of primary hyperparathyroidism. Korean J Otolaryngol-Head Neck Surg 2006;49(7):733-9.

32) Jung EJ, Seo KH, Kim WS, Jung KY. A case of nonfunctioning parathyroid carcinoma. Korean J Otolaryngol-Head Neck Surg 2002;45(3):303-5.

33) Kleinpeter KP, Lovato JF, Clark PB, Wooldridge T, Norman ES, Bergman S, et al. Is parathyroid carcinoma indeed a lethal disease? Ann Surg Oncol 2005;12(3):260-6.

34) Asare EA, Sturgeon C, Winchester DJ, Liu L, Palis B, Perrier ND, et al. Parathyroid carcinoma: An update on treatment outcomes and prognostic factors from the National Cancer Data Base (NCDB). Ann Surg Oncol 2015;22(12):3990-5. 